\title{
Application of polyester derived from biomass in petroleum asphalt cement
}

\author{
Fernando de Araújo ${ }^{1}$, Ingrid Souza Vieira da Silva ${ }^{1}$ and Daniel Pasquini ${ }^{*}$ * \\ 'Institute of Chemistry, Universidade Federal de Uberlândia - UFU, Uberlândia, MG, Brazil \\ *pasquini@iqufu.ufu.br
}

\begin{abstract}
This study evaluated the effects of the incorporation of a new additive to asphalt cement oil (CAP). A polyol product was obtained through the oxypropylation reaction of sugarcane bagasse. This polyol was polymerised with pyromellitic anhydride in order to obtain a polyester (BCP) to test its suitability in terms of the material properties to be applied as additives. FTIR spectra of the polymerised material (BCP) confirmed the occurrence of chemical modification due to the appearance of a new band at $1750 \mathrm{~cm}^{-1}$, characteristic of ester groups. The TGA data showed that the BCP product had higher thermal stability than the polyol. According to the softening point and elastic recovery tests, the incorporation of $11 \%$ and $16 \% \mathrm{w} / \mathrm{w}$ BCP in conventional CAP met the specifications of regulatory standards.
\end{abstract}

Keywords: petroleum asphalt cement, polyol, polyesters, sugarcane bagasse.

\section{Introduction}

For most road applications, conventional asphalt exhibits good behaviour which satisfies the requirements necessary for proper performance in traffic and under normal weather conditions. However, as the volume of commercial vehicles, weight, and increasing axle size, continues to grow year by year, on special highways or airports, or in corridors with heavy traffic and adverse weather conditions, with large temperature differences between winter and summer, it has become increasingly necessary to modify and improveing the properties of asphalt ${ }^{[1]}$. Among the modifications that have been investigated are natural asphalt, gilsonita or asphaltite, but especially polymers of various kinds that improve the performance of the binder.

A petroleum derivative, known as petroleum asphalt cement (CAP) in Brazil, is often used as the binder of the mineral aggregates. It is a semi-solid material, dark brown to black in colour, waterproof, viscoelastic, is slightly reactive and exhibits adhesive and thermoplastic properties. The addition of polymers to the CAP tends to improve the viscoelastic properties, providing greater stability to the road surface ${ }^{[2]}$. The use of polymer-modified asphalts can reduce the frequency of maintenance and increase the life-time of local service roads which are difficult to access or suffer from a high-cost penalty for traffic interruption, should repairs be required ${ }^{[1]}$. Due to its low cost, abundance and easy availability, sugarcane bagasse (BC) is often used as a raw material for oxypropylation reactions with a view to producing a viscous polyol (BCO). This reaction makes the hydroxyls of the starting biomass (BC) more accessible for further reactions. Due to the high reactivity of anhydrides, the condensation polymerisation reaction of BCO and pyromellitic anhydride were carried out, which were aimed at producing an elastomeric copolymer type polyester (BCP) with desirable characteristics comparable to conventional CAP.
As CAP constitutes 25 to $40 \%$ of the coating cost $t^{[1]}$, it is feasible to study the applicability of the polymerised material (BCP) as an alternative source to reduce the production cost of the petrochemical CAP. Furthermore it offers environmental benefits, due to the added value of the materials that until now, did not offer noble applications.

\section{Materials and Methods}

\subsection{Obtaining sugarcane bagasse}

The $\mathrm{BC}$ was obtained from a plantation located in Monte Alegre-MG. The sample was ground in a Willey mill and subsequently sieved through sieves with a 35 and 80 mesh. The fractions collected between these screens, with dimensions of 0.425 by $0.180 \mathrm{~mm}$, were used for the oxypropylation reaction.

\subsection{Oxypropylation of sugarcane bagasse}

For the oxypropylation reaction, $5 \mathrm{~g}$ of the $\mathrm{BC}$ sample was added to $50 \mathrm{~mL}$ of an ethanol solution containing $0.5 \mathrm{~g}$ of $\mathrm{KOH}$ and then maintained in an oven for $12 \mathrm{~h}$ at $105^{\circ} \mathrm{C}$ to allow for sample drying and solvent evaporation. After ethanol evaporation, $25 \mathrm{~mL}$ of propylene oxide (OP) was added to the BC sample in a $300 \mathrm{~mL}$ stainless steel autoclave. The sealed autoclave, equipped with a thermocouple, a pressure gauge, and a heater controller system, was then heated at a heating rate of $5^{\circ} \mathrm{C} \mathrm{min}^{-1}$, to $200{ }^{\circ} \mathrm{C}$ while the increasing corresponding pressure was monitored. The finalization of the oxypropylation reaction was revealed by increasing the pressure followed by a reduction to atmospheric pressure which results in the total consumption of OP. The resulting material was a viscous polyol (BCO). 


\subsection{Procedure for the polymerisation of the elastomeric copolymer}

For this polymerisation reaction, $20 \mathrm{~g}$ of $\mathrm{BCO}, 1 \mathrm{~g}$ of sodium acetate (catalyst) and $8 \mathrm{~g}$ of pyromellitic anhydride (AP), were added to a stainless steel autoclave and allowed to react for 30 minutes at $200^{\circ} \mathrm{C}$. The elastomeric copolymer type polyester product was identified as BCP.

\subsection{Analyses of Fourier transform infrared spectroscopy (FTIR)}

The samples of $\mathrm{BC}, \mathrm{BCO}, \mathrm{AP}$ and $\mathrm{BCP}$ were characterised by the FTIR analysis of $\mathrm{KBr}$ disks prepared with $1 \mathrm{mg}$ of the sample per $100 \mathrm{mg}$ of $\mathrm{KBr}$, using a Shimadzu IR-21 PRESTIGE spectrometer. Infrared spectra were obtained in the range of 4000 to $400 \mathrm{~cm}^{-1}$, with a spectral resolution of $4 \mathrm{~cm}^{-1}$ and 32 scans.

\subsection{Solubility test}

Solubility tests of BCP were performed in different solvents. For each solvent $(25 \mathrm{~mL}) 0.15 \mathrm{~g}$ of BCP was added, and the mixture was kept for 24 hours at room temperature, after which its solubility was analysed. The solvents used were: acetone, water, chloroform, ethanol and hexane.

\subsection{Thermogravimetric analysis (TGA)}

The thermal stabilities of the $\mathrm{BC}, \mathrm{BCO}, \mathrm{AP}$ and $\mathrm{BCP}$ samples were tested with a Shimadzu DTG-60H machine. Around 5 to $7 \mathrm{mg}$ of each sample was put into an aluminium pan and heated from 25 to $600{ }^{\circ} \mathrm{C}$ at a heating rate of $10{ }^{\circ} \mathrm{C} \mathrm{min}{ }^{-1}$ under a nitrogen atmosphere with a flow rate of $50 \mathrm{~mL} \mathrm{~min}^{-1}$.

\subsection{Preparation of the modified CAP with $B C P$}

Analysis of the modified CAP with BCP as well as the characterization of conventional CAP (30/45) and the modified CAP were made in the quality control lab of BT Construction Ltd., located in Uberlândia MG.

The BCP and CAP samples (30/45) supplied by the company were maintained at $105^{\circ} \mathrm{C}$ for a period of $8 \mathrm{~h}$ to evaporate any residual water, which would interfere with the preparation procedure of the premixture of both. Then, both CAP and BCP were heated to approximately $150^{\circ} \mathrm{C}$ on a heating plate in separate containers for approximately 40 minutes. $11 \%, 16 \%$ and $21 \% \mathrm{w} / \mathrm{w}$ of $\mathrm{BCP}$, in relation to a total CAP mass of $600 \mathrm{~g}$, was added in order to evaluate how the incorporation of the additive would affect the properties of the modified CAP.

Then, to prepare the premixture, both the CAP (30/45) and the incorporated $\mathrm{BCP}$ were subjected to vigorous stirring for approximately 40 minutes on a heating plate with a temperature controller set to $150^{\circ} \mathrm{C}$. The premix was stored in an oven at $150^{\circ} \mathrm{C}$ for 8 hours before subsequent softening point and ductility test characterization.

\subsection{Softening point test}

The softening point test refers to an empirical measure that correlates to the temperature at which materials, in this case asphalt, soften when heated under certain specific conditions and reach a predetermined flow level. In this assay, the samples were CAP (30/45), which is one of the materials used in the production of asphalt by the BT construction company, and was compared to the modified BCP-CAP prepared for this study.

The test samples in the form of ring and ball, were completed with the modified BCP-CAP. The test samples were kept at room temperature, approximately $25^{\circ} \mathrm{C}$, and were immersed in a glass beaker for 30 minutes. They were then placed on a controlled heating plate and the glass beaker containing the test samples was heated at a rate of $5{ }^{\circ} \mathrm{C}$ per minute. These assays were performed in duplicate and conformed to DNER 382/99 standards ${ }^{[3]}$. Conventional CAP (30/45) was subjected to the same analysis.

\subsection{Ductility test}

Ductility refers to the ability of a material to stretch in the form of a filament. This test was performed to evaluate the cohesion of asphalt. To perform this test, both of the test samples were analysed with the CAP and the modified $\mathrm{BCP}-\mathrm{CAP}$, respectively. The test samples were maintained at room temperature, approximately $25^{\circ} \mathrm{C}$.

Then, they were cut with tweezers so that the surface of both of the test samples were the same, thus ensuring that there were no alterations to the diameter of the samples, when stretched for the test run.

Prior to the ductility test, a preliminary step of correcting the density of the water present inside the machine was carried out, with sugar (sucrose), with respect to the density of the modified CAP, whose density was determined by pycnometry. Adjusting the density of the water present inside the machine above the density of the CAP was necessary to ensure complete immersion of the test samples in the machine, so that when stretched, the samples still remained fully immersed. The ductility metre was maintained at $25^{\circ} \mathrm{C}$ and then the test samples were immersed in the equipment and were programmed to be stretched to $20 \mathrm{~cm}$. When this $20 \mathrm{~cm}$ stretching value was reached, the equipment automatically disconnected.

The system was then left undisturbed for 90 minutes, after which the manual recoverable strain times for the immersed test samples were given in $\mathrm{cm}$. After these measurements, the system was left undisturbed again for 60 minutes, and then another recoverable deformation cycle was measured.

The elastic recovery of each test sample was calculated as the ratio between the value found after the 60 minutes and the value recorded in the first measurement $(20 \mathrm{~cm})$. These assays were performed in duplicate and were performed in accordance with DNER 382/99 $\operatorname{standards}^{[3]}$.

\subsection{Proof body moulding}

To shape the test samples, the norm, as defined in DNER ME $043 / 95$ was adopted ${ }^{[4]}$, known as the Marshall dosage method of asphalt mixtures. A standard trace was used, as determined by the standards, to calculate the quantity of aggregates needed to shape the test samples using the modified BCP-CAP, as shown in Table 1. This approach was similarly applied for the CAP (30/45) samples. 
For the mixture detailed in Table 1, 4.8\% w/w of conventional CAP or modified BCP-CAP, was added.

Marshall compaction was used in an effort consisting of 25 blows with a socket proctor, followed by the application of a static load of 5,000 pounds for two minutes, with the intention of levelling the test sample surfaces.

\subsection{Proof body characterization}

\subsubsection{Percentage of empty volume}

This parameter is important for characterising the behaviour of asphalt mixtures because it has a significant influence on their cohesion and stiffness properties. The percentage of empty $\left(\% \mathrm{~V}_{\mathrm{v}}\right)$ is defined as the relationship between the empty volume and the total volume of the mixture, and was calculated according to Equation $1^{[1]}$ :

$$
\% \text { Empty }_{\text {volumes }}=\frac{\text { Theoretical }_{\text {density }}-\text { Specific }_{\text {density }}}{\text { Theoretical }_{\text {density }}}
$$

\subsubsection{Percentage of minerals empty and Bitumen empty relation}

The percentage of mineral empty $\left(\mathrm{V}_{\mathrm{AM}}\right)$ represents the volume of intergranular empty spaces between the aggregate particles and the compacted mixture. This parameter was calculated according to Equation $2^{[1]}$ :

$$
V_{A M}=\frac{\% V_{V} \times \text { Volume }_{C A P}}{\text { Volume }_{\text {total }}} \times 100
$$

Additionally, this parameter was in-turn used to calculate a parameter called the Bitumen Empty Relation $\left(R_{B V}\right)$ defined in Equation $3^{[1]}$ :

$$
R_{B V}=\frac{\% V_{V}}{V_{A M}} \times 100
$$

\subsubsection{Fluency and stability}

This assay was performed for both of the test samples prepared with CAP (30/45) and the modified BCP-CAP in order to determine the mechanical parameters, fluency and stability. In this assay, the test samples were stored in a thermostatic bath with a temperature controller set to $60{ }^{\circ} \mathrm{C}$ for 40 minutes. Then, the test samples were placed in a compression mould used for this assay. The compression mould was coupled to the Marshall press to determine the maximum load which the test samples could withstand before rupture, defined as stability, as well as the vertical displacement corresponding to the application of the maximum load supported by test samples, defined as fluency ${ }^{[1]}$.

Table 1. Aggregate type for shape test samples of the modified BCP-CAP and CAP (30/45).

\begin{tabular}{cc}
\hline Aggregate type & Quantity (\%) \\
\hline Crushed stone 3/4” & 18.0 \\
Crushed stone 0 & 32.0 \\
Stone powder & 45.0 \\
Limestone & 5.0 \\
\hline
\end{tabular}

\section{Results and Discussion}

Figure 1 shows the FTIR spectra for the samples denoted $\mathrm{BC}, \mathrm{BCO}, \mathrm{AP}$ and $\mathrm{BCP}$. The major peaks observed in the spectra were the BC bands at approximately $3300-3900 \mathrm{~cm}^{-1}$ which can be attributed to the $\mathrm{OH}$ stretch of cellulose, hemicellulose and lignin. The band observed at around $2800-3000 \mathrm{~cm}^{-1}$ can be attributed to aliphatic $\mathrm{CH}$ bonds, the band around $1675-1759 \mathrm{~cm}^{-1}$ is most likely associated with the carbonyl groups $(\mathrm{C}=\mathrm{O})$ present in the lignins and hemicelluloses, bands around 1000-1250 $\mathrm{cm}^{-1}$ which are characterisitic of C-O bonds that correspond to ethers link structures present in lignin, cellulose and hemicellulose, and a band at $1515 \mathrm{~cm}^{-1}$ which is indicative of the presence of lignin and can be attributed to the $\mathrm{C}=\mathrm{C}$ vibration of aromatic rings ${ }^{[5]}$. For the oxypropylated $\mathrm{BCO}$ samples, an increase in $\mathrm{CH}$ aliphatic bands from of 2800 to $3000 \mathrm{~cm}^{-1}$ was observed, with the appearance of a new peak at $2970 \mathrm{~cm}^{-1}$ associated with methyl groups due to the grafted OP units. The increase of the peak associated with the CO groups, as observed from $1000-1100 \mathrm{~cm}^{-1}$, can be attributed to the insertion of ether groups of OP. The FTIR spectra shown in Figure 1 confirm BC chemical modification when compared to the modified residue of BCO. These spectra also confirm the chemical modification process by oxypropylation, confirming the presence of the OP homopolymer formed during the oxypropylation reaction ${ }^{[6]}$.

The AP FTIR spectrum, shown in Figure 1 shows AP characteristic bands near $1775 \mathrm{~cm}^{-1}$ which can be assigned to $\mathrm{C}=\mathrm{O}$ stretching, and the regions $1225 \mathrm{~cm}^{-1}$ and $926 \mathrm{~cm}^{-1}$ can be associated with the $\mathrm{C}-\mathrm{O}$ stretch of the cyclic anhydrides ${ }^{[7]}$. From the BCP spectrum it was possible to observe the appearance of a new peak at around $1759 \mathrm{~cm}^{-1}$, which confirms the polymerisation of $\mathrm{BCO}$ with $\mathrm{AP}$, leading to the formation of the $\mathrm{BCP}$ polyester copolymer, due to the introduction of $\mathrm{C}=\mathrm{O}$ groups, which can be observed for wavelengths associated with carbonyl esters.

From the thermograms of Figure 2, obtained in the thermogravimetric analysis, it is observed that $\mathrm{BC}$ has the higher comparative thermal stability, and the degradation profile is typical of a lignocellulosic material. The BCO has low thermal stability due to its viscous liquid state characteristics. After the polymerisation reaction, there was an increase in the stability of the resulting BCP polyester.

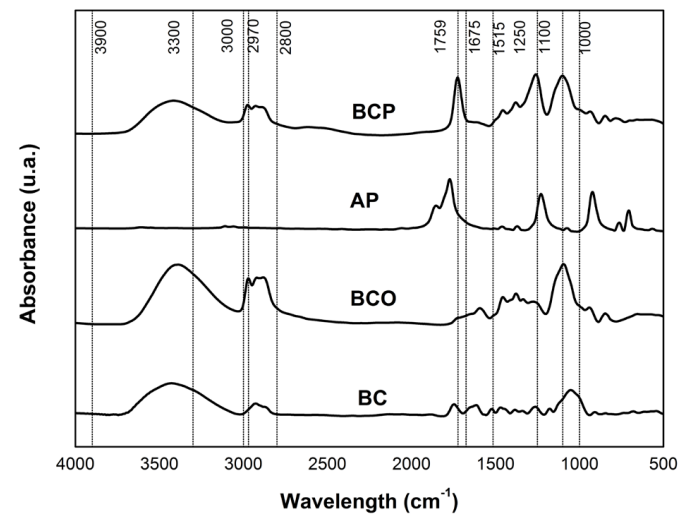

Figure 1. FTIR spectra of $\mathrm{BC}, \mathrm{BCO}, \mathrm{AP}$ and $\mathrm{BCP}$. 
Degradation temperatures ( $\mathrm{T}$ on set), obtained by the method of tangents in thermograms, were $260^{\circ} \mathrm{C}$ for $\mathrm{BC}, 95^{\circ} \mathrm{C}$ for $\mathrm{BCO}$ and $187^{\circ} \mathrm{C}$ for BCP.

In the solubility tests, conducted with BCP in different solvents, it was observed that BCP was not soluble in water, chloroform and hexane, and was partially soluble in ethanol and acetone. Solubility in water is a critical factor for possible applications of CAP formulations, as it essential to ensure that $\mathrm{BCP}$ will not solubilise with rain water, ensuring that premature repairs are not required. The solubility tests also showed that BCP is probably a crosslinked polymer due to its lack of solubility in the solvents tested. The results obtained, in terms of thermal stability and solubility, show that $\mathrm{BCP}$ has characteristics which are compatible with improved performance upon addition to CAP formulations.

The potential of BCP as an additive for conventional CAP was evaluated using the softening point and elastic recovery assays, and compared to conventional CAP. The values were compared with current standards (DNER $382 / 385)^{[3]}$. These parameters are considered essential in identifying the potential of the materials studied for the intended applications, and provide grants in accordance with the consulted standards (DNER 382/385) ) $^{[3]}$. The incorporation of this additive would cause changes in these parameters, and the application of this additive would hamper use of the modified CAP for the desired application if the results were deemed not to align with the recognised standards.

Here, the effect on the properties of conventional CAP upon the incorporation of $11 \%$ and $16 \% \mathrm{w} / \mathrm{w}$ of BCP, as well as compliance of these parameters, in terms of aligning with the specifications of existing rules, was investigated and is reported. The addition of $21 \% \mathrm{w} / \mathrm{w}$ of BPC was incompatible with the CAP and a phase separation was observed. So it was not possible to carry out the tests for this composition.

Table 2 presents the results obtained during the characterisation of the conventional CAP and modified CAP with the additive BCP.

According to the data shown in Table 2, the values found during tests, the BCP-CAP showed comparable values when compared to conventional CAP and followed the specifications of existing rules. Rose and co-workers reported that modified asphalt containing $12 \%$ recycled

Table 2. Parameters used in the characterisation of CAP.

\begin{tabular}{lcc}
\hline \multicolumn{1}{c}{ CAP } & $\begin{array}{c}\text { Softening } \\
\text { Point }\left({ }^{\circ} \mathbf{C}\right)\end{array}$ & $\begin{array}{c}\text { Elastic } \\
\text { Recovery }(\%)\end{array}$ \\
\hline DNER 382/385 standards & $60.0 \pm 1.0$ & $85.0 \pm 1.0$ \\
Conventional & $63.9 \pm 3.0$ & $83.7 \pm 1.5$ \\
CAP with 11\% w/w BCP additive & $64.0 \pm 3.0$ & $83.5 \pm 1.5$ \\
CAP with 16\% w/w BCP additive & $62.8 \pm 3.0$ & $83.8 \pm 1.5$ \\
\hline
\end{tabular}

rubber tyres had a softening point of $57.5^{\circ} \mathrm{C}$ and an elastic recovery of $79.8 \%{ }^{[8]}$. D'Antona and co-workers reported that when $4 \%$ of a copolymer of ethylene and vinyl acetate (EVA) was added to conventional CAP, the softening point value was $62.3^{\circ} \mathrm{C}^{[9]}$.

Considering the above findings, the application of $\mathrm{BCP}$ as an additive does not prevent the use of modified CAP for the preparation of asphalt, and corroborates the data previously reported in the literature ${ }^{[8,9]}$.

In addition, the test samples were moulded using the Marshall compactor manual following the norm according to DNER ME 043/95 ${ }^{[4]}$. Figure 3 shows the test sample of BCP-CAP produced in cylindrical form.

Table 3 shows the results obtained from the Marshall test, which present the specific parameters used to characterise the proof bodies produced using the conventional CAP and the modified BCP-CAP.

Tayfur and co-workers investigated the addition of 7\% of a styrene butadiene copolymer (SB) and 7\% of cellulose fibre $(\mathrm{CF})$ to asphalts. The values found for stability were

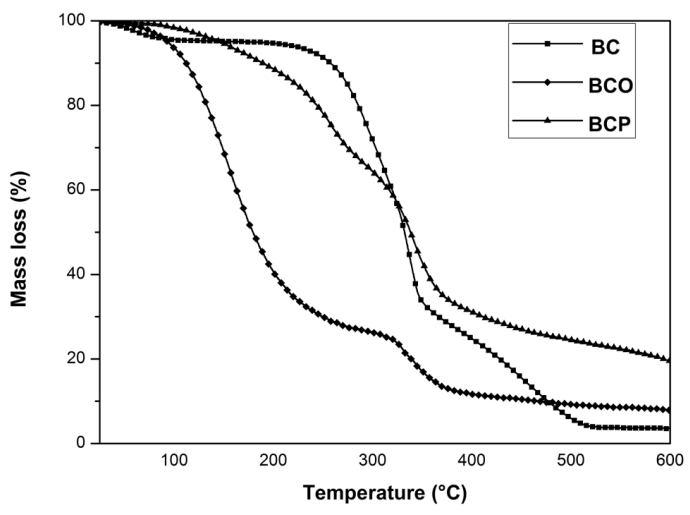

Figure 2. Thermograms of $\mathrm{BC}, \mathrm{BCO}$ and $\mathrm{BCP}$ samples.
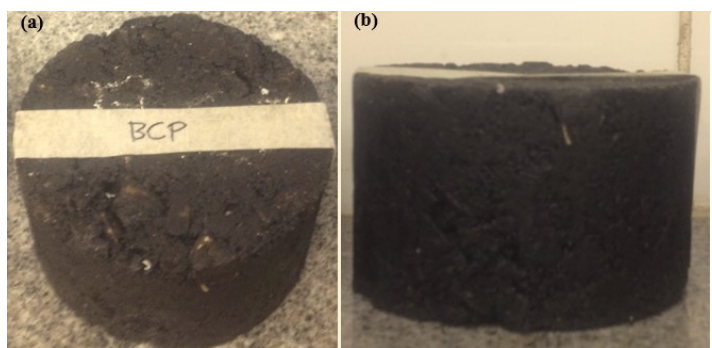

Figure 3. (a) BCP modified CAP proof bodies in cylindrical form - top view; (b) BCP modified CAP proof bodies in cylindrical form - side view.

Table 3. Marshall test results.

\begin{tabular}{lcccc}
\hline \multicolumn{1}{c}{ Parameters } & $\begin{array}{c}\text { Conventional } \\
\text { CAP 30/45 }\end{array}$ & $\begin{array}{c}\text { CAP Modified with BCP } \\
\mathbf{( 1 1 \%} \mathbf{~ w / w )}\end{array}$ & $\begin{array}{c}\text { CAP Modified with BCP } \\
\mathbf{( 1 6 \%} \mathbf{w} / \mathbf{w})\end{array}$ & $\begin{array}{c}\text { Standard } \\
\text { Marshall }\end{array}$ \\
\hline Empty (\%) & 4.3 & 5.1 & 4.1 & $3-5$ \\
Relation empty bitumen (\%) & 73.4 & 70.1 & 74.7 & $65-75$ \\
Stability (kgf) & 976 & 965 & 917 & $>500$ \\
Fluency (mm) & 3.2 & 3.2 & 3.2 & $2-4.5$ \\
\hline
\end{tabular}


$695 \mathrm{kgf}$ for $\mathrm{SB}$ and $690 \mathrm{kgf}$ for $\mathrm{CF}$, the $\mathrm{V}_{\mathrm{v}}$ to the percentage of SB was $3.80 \%$ and was $3.90 \%$ for $\mathrm{CF}$, and finally the values found for fluency were $4.35 \mathrm{~mm}$ for $\mathrm{SB}$ and $3.90 \mathrm{~mm}$ for $\mathrm{CF}$. In view of these results, the values found for the modified asphalt with BCP, in terms of stability, was on average $33 \%$ to $39 \%$ higher than the values found by Tayfur et al. ${ }^{[10]}$. The percentage of $\mathrm{V}_{\mathrm{v}}$ was on average $8 \%$ to $32 \%$ higher than the values found by Tayfur et al. ${ }^{[10]}$.

A study by D'Antona and co-workers reported on the incorporation of $4 \%$ of an ethylene and vinyl acetate copolymer (EVA) to conventional CAP, and reveals a Bitumen empty relation (\%) value of $65.5 \%{ }^{[9]}$. Thus, the modified asphalt with the $\mathrm{BCP}$ additive, in terms of this parameter, was on average $7 \%$ to $14 \%$ higher than the values found by D'Antona et al..

In this sense, the comparative analysis, in terms of the parameters studied with the asphalt produced using the BCP additive, has properties superior to previously published data with other additives ${ }^{[9,10]}$. The comparative analysis of the data shown in Table 3 indicates that the incorporation of the $\mathrm{BCP}$ additive to CAP is in accordance with the specifications of the DNER ME 043/95 standards $^{[4]}$ (Marshall method).

\section{Conclusion}

Based on these results it was observed that the oxypropylation reaction of $\mathrm{BC}$ was effective in producing a viscous polyol, $\mathrm{BCO}$, which can be used in the synthesis of new polymers. This reaction can be regarded as a green chemistry process as all of the material that was added to the autoclave was removed as a product in the form of a polyol.

The FTIR results confirm the polymerisation reaction of BCO with AP, generating a type of polyester copolymer referred to as BCP. TGA tests showed that the BCP copolymer obtained exhibited increased thermal stability compared to the $\mathrm{BCO}$ monomer used in the polymerisation. Solubility tests indicate that the BCP is not soluble or is partially soluble in solvents with a wide range of polarity, indicating that BCP is most likely a crosslinked polymer.

It was possible to use BCP-CAP for the production of asphalt, and according to the specific characterisations used (Marshall test), the asphalt produced meets the specifications of regulatory standards, which enables the use of the new additive for asphalt production.

Whereas both mixtures with $11 \%$ and $16 \% \mathrm{w} / \mathrm{w} \mathrm{BCP}$ presented results according to the standards, and considering the environmental aspect, we conclude that the addition of $16 \% \mathrm{w} / \mathrm{w} \mathrm{BCP}$ is the best condition due to the fact of using a larger volume of renewable source of material as additve in CAP.

\section{Acknowledgements}

The authors acknowledge CNPq, FAPEMIG and Capes for financial support, and BT Construction forworking in partnership.

\section{References}

1. Bernucci, L. B., \& Motta, L. M. G. (2008). Pavimentação asfáltica: formação básica para engenheiros. Rio de Janeiro: Universidade Petrobras.

2. Amaral, S. C. (2000). Estudo de misturas densas com agregados do estado do Pará, utilizando asfalto convencional (CAP-40) e asfalto modificado com polímero SBS (Betuflex B 65/60) (Master's dissertation). Universidade de São Paulo, São Carlos.

3. Departamento Nacional de Estradas e Rodagem - DNER. (1999). Normas 382/1999: determinação da recuperação elástica de asfálticos modificados por polímeros, pelo método do ductilometro. Rio de Janeiro: DNER.

4. Departamento Nacional de Estradas e Rodagem - DNER. (1995). Normas 043/1995: misturas betuminosas a quente: ensaio Marshal. Rio de Janeiro: DNER.

5. Silvério, H. A., Flauzino, W. P., No., Dantas, N. O., \& Pasquini, D. (2013). Extraction and characterization of cellulose nanocrystals from corncob for application as reinforcing agent in nanocomposites. Industrial Crops and Products, 44, 427-436. http://dx.doi.org/10.1016/j.indcrop.2012.10.014.

6. Menezes, A. J., Pasquini, D., Curvelo, A. A. S., \& Gandini, A. (2009). Self-reinforced composites obtained by the partial oxypropylation of cellulose fibers. 1 . Characterization of the materials obtained with different types of fibers. Carbohydrate Polymers, 76(3), 437-442. http://dx.doi.org/10.1016/j. carbpol.2008.11.006.

7. Oliveira, V. A. (2008). Síntese e caracterização de géis de acetato de celulose reticulados com dianidrido piromelítico e dianidrido do ácido 3,3',4,4'benzofenona tetracarboxílico (Master's dissertation). Universidade Federal de Ouro Preto, Ouro Preto.

8. Rosa, A. P. G., Santos, R. A., Crispim, F. A., \& Riva, R. D. D. (2012). Análise comparativa entre asfalto modificado com borracha reciclada de pneus e asfalto modificado com polímeros. Teoria e Prática na Engenharia Civil, 20, 31-38. Retrieved in 23 December 2016, from http://www.editoradunas. com.br/revistatpec/Art4_N20.pdf

9. D’Antona, D. M. G., \& Frota, C. A. (2011). Estudo de Misturas Asfálticas com Ligante Modificado pelo Polímero EVA para Pavimentos Urbanos de Manaus - AM. Polímeros: Ciência e Tecnologia, 21(1), 13-18. http://dx.doi.org/10.1590/S010414282011005000007.

10. Tayfur, S., Ozen, H., \& Atakan, A. (2007). Investigation of rutting performance of asphalt mixtures containing polymer modifiers. Carbohydrate Polymers, 21(2), 328-337. http:// dx.doi.org/10.1016/j.conbuildmat.2005.08.014.

Received: Dec. 23, 2015

Revised: June 18, 2016

Accepted: June 29, 2016 